\title{
Chloroform fraction of Serratulae chinensis S. Moore suppresses proliferation and induces apoptosis via the phosphatidylinositide 3-kinase/Akt pathway in human gastric cancer cells
}

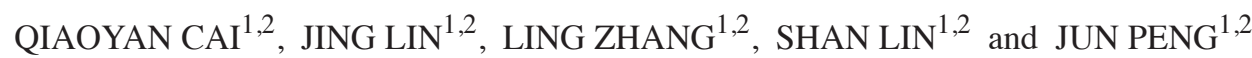 \\ ${ }^{1}$ Academy of Integrative Medicine; ${ }^{2}$ Fujian Key Laboratory of Integrative Medicine on Geriatrics, \\ Fujian University of Traditional Chinese Medicine, Fuzhou, Fujian 350122, P.R. China
}

Received September 20, 2016; Accepted August 3, 2017

DOI: $10.3892 / \mathrm{ol} .2018 .8366$

\begin{abstract}
The chloroform fraction of the folk Chinese medicine, Serratulae chinensis S. Moore (CSC) and its anti-inflammatory activity is well recognized. However, the molecular mechanisms underlying the beneficial anticancer effects of CSC remain largely unknown. The aim of the present study was to examine the effects of CSC on the regulation of cell proliferation and apoptosis in SGC-7901 gastric cancer cells, as well as to investigate the underlying molecular mechanisms involved. The results from the present study demonstrated that CSC treatment inhibited SGC-7901 cell viability and survival in a dose- and/or time-dependent manner. CSC treatment further induced the apoptosis of SGC-7901 cells, characterized by distinct chromatin condensation and fragmented nuclear morphology. In addition, CSC treatment suppressed protein kinase-B (Akt) phosphorylation and phosphatidylinositide 3-kinase (PI3K) expression in SGC-7901 cells, which in turn promoted cancer cell apoptosis and inhibited cell proliferation. Furthermore, CSC treatment altered the expression pattern of several key target genes of the PI3K/Akt signaling pathway through the downregulation of Cyclin D1, cyclin-dependent kinase-4 and B-cell lymphoma-2 and the upregulation of Bcl-2-associated X protein. Therefore, the results from the present study demonstrated that CSC suppressed cell survival and induced apoptosis in human gastric cancer cells, via targeting the PI3K/Akt pathway.
\end{abstract}

\section{Introduction}

Gastric cancer (GC) is one of the most commonly diagnosed malignant cancers, with the third leading cause of cancer-related death worldwide $(1,2)$. Although surgery, chemotherapy and

Correspondence to: Dr Jun Peng, Academy of Integrative Medicine, Fujian University of Traditional Chinese Medicine, 1 Qiuyang Road, Fuzhou, Fujian 350122, P.R. China

E-mail: pjunlab@hotmail.com

Key words: Serratulae chinensis, gastric cancer, phosphatidylinositide 3-kinase/protein kinase-B pathway, apoptosis, proliferation radiation therapy are the main conventional treatments for $\mathrm{GC}$, its effect is limited in disease control, and the median overall survival time is $<1$ year (3). Due to the lack of effective treatments currently available for patients with advanced GC, the development of novel and effective anticancer agents with minimal toxicity is crucial (4). In previous years, traditional Chinese medicinal herbs have received increased recognition and are now considered to be an important source in the development of novel and effective anticancer agents, with relatively few side effects $(5,6)$. Previously, a considerable number of promising anticancer agents that have been isolated from Chinese herbs have been identified $(7,8)$, shedding new light on potential therapeutic strategies for cancer treatment.

Signaling transduction pathways regulate all major cellular events in health and disease (9). The phosphatidylinositide 3-kinase (PI3K)/protein kinase-B (Akt) pathway is a crucial signaling transduction pathway involved in cellular proliferation and apoptosis; and is activated in multiple types of cancer (10-13). Phosphorylation of Akt is mediated by the activation of plasma membrane-localized 3-phosphoinositide-dependent protein kinase 1 (PDK1), which when inhibited is associated with the inhibition of cancer cell proliferation (14). Alterations in Akt signaling are known to be associated with tumor cell survival and proliferation; in addition to the inhibition of apoptosis via the upregulation of apoptotic associated factors, including B-cell lymphoma-2 (Bcl-2), B-cell lymphoma-extra large (Bcl-xL) and $\mathrm{Bcl}-2$-associated $\mathrm{X}$ protein (Bax) $(15,16)$. Therefore, inhibition of the PI3K/Akt pathway with proteasome inhibitors may potentially be an alternative strategy for the treatment of gastric cancer $(17,18)$.

Serratulae chinensis S. Moore (SC; also known as Guang Sheng Ma), belonging to the composite family, is a medicinal herb widely distributed in southern China. In traditional Chinese medicine (TCM), the rhizome of SC is used for detoxification, promotion of blood circulation $(19,20)$ and has been commonly used as an anti-inflammatory agent, analgesic, and antipyretic agent in TCM. Pharmacological studies have demonstrated that it contains compounds with anti-inflammatory, analgesic, antipyretic and anticancer activities, including ceramides and flavones $(21,22)$. However, previous research has mainly focused on the isolation of components of SC rather than the biological activity. Therefore, the 
aim of the present study was to evaluate the anticancer effects of SC on the proliferation, colony formation and apoptosis of gastric cancer cells.

\section{Materials and methods}

Materials and reagents. Dulbecco's modified Eagle's medium (DMEM), fetal bovine serum (FBS), penicillin-streptomycin, trypsin-EDTA and phosphate-buffered saline (PBS) were all purchased from HyClone; GE Healthcare Life Sciences (Logan, UT, USA). TRIzol reagent and the SuperScript II reverse transcriptase kit were purchased from Invitrogen; Thermo Fisher Scientific, Inc. (Waltham, MA, USA). PI3K (cat. no. 4249), Akt (cat. no. 4691), phosphorylated (p-)Akt (cat. no. 4060), Bcl-2 (cat. no. 3498), Bax (cat. no. 5023), Cyclin D1 (cat. no. 2978), CDK4 (cat. no. 12790) antibodies and horseradish peroxidase (HRP)-conjugated secondary antibodies (anti-rabbit IgG; cat. no. 7074) were obtained from Cell Signaling Technology, Inc. (Danvers, MA, USA). All other chemicals used, unless otherwise stated, were obtained from Sigma-Aldrich; Merck KGaG (Darmstadt, Germany).

Preparation of CSC. The aerial parts of SC were purchased from Shanghang county (Longyan, China) and identified by Professor Cheng-zi Yang of the Department of Pharmacy, Fujian University of Traditional Chinese Medicine (Fuzhou, China). To prepare the CSC, SC (500 g) was extracted three times with 5,000 $\mathrm{ml}$ 95\% ethanol using a reflux method, followed by filtering with qualitative filter paper (Hangzhou Xinhua Paper Industry Co. Ltd., Hangzhou, China). The solvent was fractionated using a series of solvents, including petroleum ether, chloroform, ethyl acetate and N-butanol. The chloroform fraction of SC (CSC) was evaporated on a rotary evaporator (Model RE-2000; Yarong Biochemistry Instrument Factory, Shanghai, China). The CSC was obtained using the spraying desiccation method with a spray dryer (Model B-290; BUCHI Labortechnik AG, Flawil, Switzerland) (23). Subsequently, powders of the extracts were dissolved in $100 \%$ DMSO to a stock concentration of $100 \mathrm{mg} / \mathrm{ml}$ and stored at $-20^{\circ} \mathrm{C}$. The final concentration of DMSO in the DMEM medium (HyClone; GE Healthcare, Logan, UT, USA) for all experiments was $<0.5 \%$. The final concentrations of CSC were $0,125,250$ and $500 \mu \mathrm{g} / \mathrm{ml}$.

Cell culture. Human gastric cancer SGC-7901 cells were obtained from the Cell Bank of Type Culture Collection of Chinese Academy of Sciences (Shanghai, China). Cells were cultured in DMEM supplemented with $10 \%$ (v/v) FBS, $100 \mathrm{U} / \mathrm{ml}$ penicillin and $100 \mu \mathrm{g} / \mathrm{ml}$ streptomycin at $37^{\circ} \mathrm{C}$ in a humidified incubator supplemented with $5 \% \mathrm{CO}_{2}$ in air.

MTT assay. Cells were cultured in DMEM medium supplemented with $0,125,250$ or $500 \mu \mathrm{g} / \mathrm{ml} \mathrm{CSC}$ for 24,48 or $72 \mathrm{~h}$. Following treatment, $20 \mu \mathrm{l}$ MTT (Invitrogen; Thermo Fisher Scientific, Inc.) was added to each well and incubated for $4 \mathrm{~h}$ at $37^{\circ} \mathrm{C}$ prior to analysis. The formazan precipitate was dissolved in $100 \mu \mathrm{l}$ DMSO. The absorbance was measured at $570 \mathrm{~nm}$ using a microplate reader (BioTek Instruments Inc., Winooski, VT, USA). Cell viability was determined using the formula: Cell viability $(\%)=$ sample optical density (OD)/control OD x 100 .
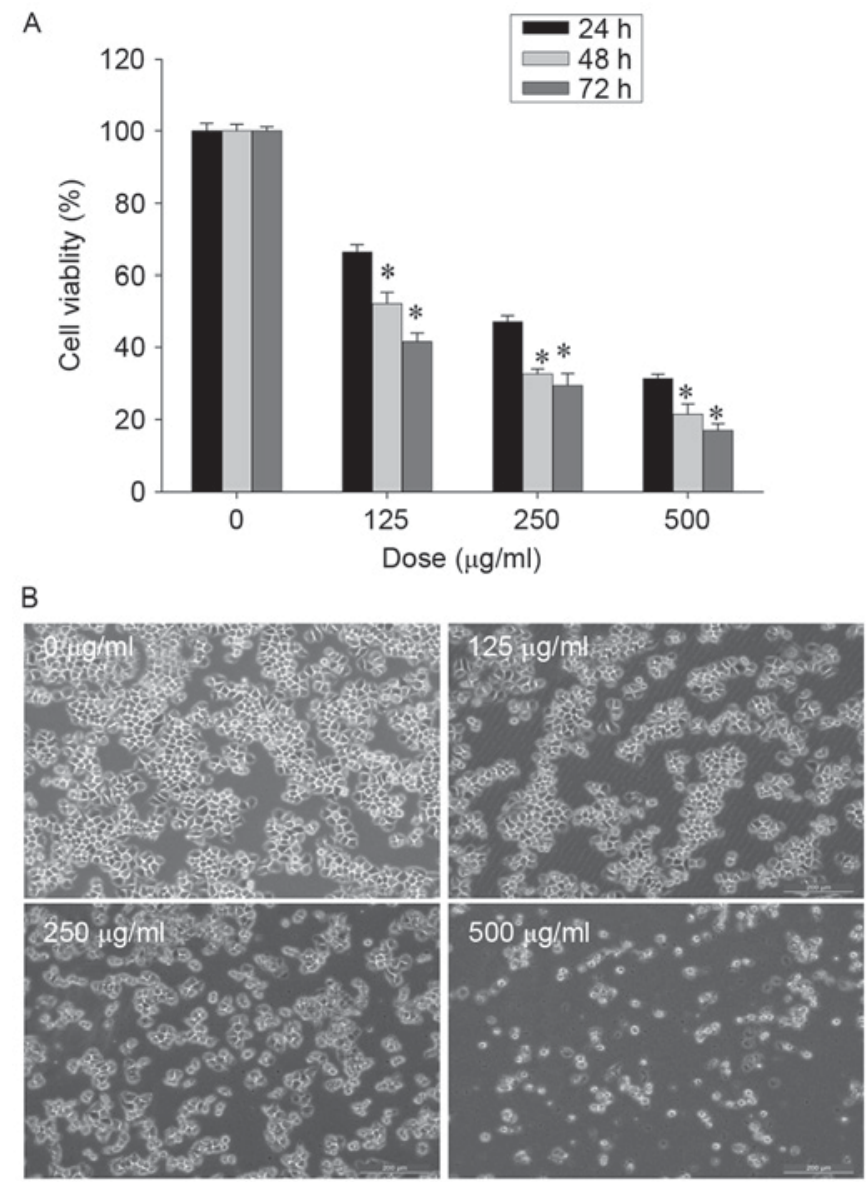

Figure 1. Effects of CSC on viability and morphology. (A) Cell viability was determined using MTT assay following treatment of SGC-7901 cells with various concentrations of CSC for 24, 48 or $72 \mathrm{~h}$. (B) Morphological changes were observed using phase-contrast microscopy, and the images were captured at a magnification of 200x. ${ }^{\text {"P }}<0.01$ vs. untreated cells. CSC, chloroform extract of Serratulae chinensis S. Moore.

Observation of morphologic changes. SGC-7901 cells were seeded at a density of $2.0 \times 10^{5}$ cells/well into 6-well plates in $2 \mathrm{ml}$ DMEM medium, supplemented with the indicated concentrations of CSC $(0,125,250$ or $500 \mu \mathrm{g} / \mathrm{ml})$ for $24 \mathrm{~h}$ at $37^{\circ} \mathrm{C}$. Cell morphology was observed using a phase-contrast microscope (Leica Microsystems, GmbH, Wetzlar, Germany; magnification, x200).

Colony formation. Cells were seeded at a density of $2.0 \times 10^{5}$ cells/well into 6-well plates in $2 \mathrm{ml}$ DMEM. Following treatment with the indicated concentrations of CSC $(0,125$, 250 or $500 \mu \mathrm{g} / \mathrm{ml}$ ) for $24 \mathrm{~h}$ at $37^{\circ} \mathrm{C}$, the cells were harvested and reseeded at a density of $1.5 \times 10^{3}$ cells/well in fresh CSC-free medium. The culture medium was renewed every three days. Following 7 days of culture, cells were fixed with $10 \%$ formaldehyde for $15 \mathrm{~min}$ at room temperature, stained with $0.01 \%$ crystal violet for $10 \mathrm{~min}$ at room temperature and photographed with digital camera (D7000; Nikon, Tokyo, Japan). The stained cell number was counted in 5 arbitrarily selected fields under a light microscope (DM1000; Leica Microsystems GmbH; magnification, x100). The cell survival rate was calculated using the survival rate of the control cells as $100 \%$. 


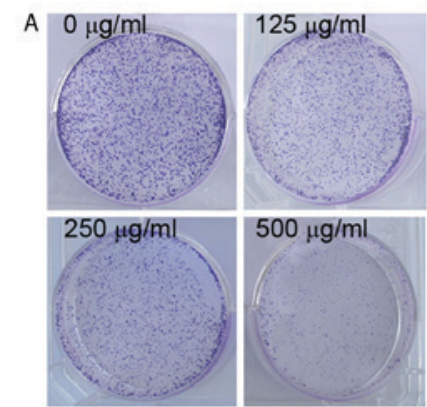

B

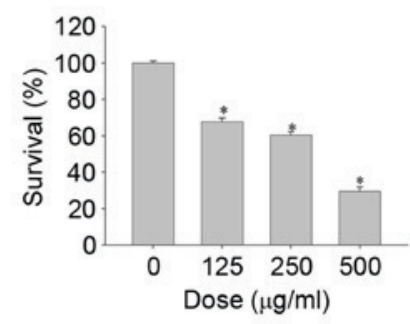

Figure 2. Effects of CSC on the proliferation of SGC-7901 cells. (A) Cell survival was determined by a colony formation assay. (B) Quantification of colony formation in SGC-7901 cells. "P<0.01 vs. untreated cells. CSC, chloroform extract of Serratulae chinensis S. Moore.

Detection of apoptosis with 4',6-diamidino-2-phenylindole (DAPI) staining. SGC-7901 cells were seeded at a density of $1.0 \times 10^{5}$ cells/well into 12 -well plates in $1 \mathrm{ml}$ DMEM. Following CSC treatment with $0,125,250$ or $500 \mu \mathrm{g} / \mathrm{ml}$ for $24 \mathrm{~h}$ at $37^{\circ} \mathrm{C}$, the level of cell apoptosis was determined using DAPI staining kit (Beyotime Institute of Biotechnology, Shanghai, China) according to the manufacturer's protocol. Briefly, cells were fixed with $4 \%$ polyoxymethylene for $10 \mathrm{~min}$ and then incubated in DAPI solution for $10 \mathrm{~min}$ in the dark at room temperature. The stained images were recorded using a phase-contrast fluorescence microscope (Leica Microsystems, $\mathrm{GmbH}$; magnification, $\mathrm{x} 400$ ). Five visual fields in each group were randomly selected.

$R N A$ extraction and reverse transcription-polymerase chain reaction (RT-PCR) analysis. Total RNA was extracted from SGC-7901 cells using TRIzol reagent according to the manufacturer's protocol. The quantity of RNA were assessed on a NanoDrop spectrophotometer (ND-2000C; Thermo Fisher Scientific, Inc.). Subsequently, first-strand cDNA synthesis was performed with $2 \mu \mathrm{g}$ total RNA using SuperScript II reverse transcriptase kit (Invitrogen; Thermo Fisher Scientific, Inc.) following the manufacturer's protocol. The cDNA was used to determine the expression levels of Bax, Bcl-2, Cyclin D1 and CDK4 mRNA using PCR with DreamTaq Green PCR Master Mix (Fermentas; Thermo Fisher Scientific, Inc.) Samples were analyzed by gel electrophoresis (1.5\% agarose) and the DNA bands were analyzed using a Gel Documentation system (Model Gel Doc 2000; BioRad Laboratories, Hercules, CA, USA). The reference gene used was glyceraldehyde 3-phosphate dehydrogenase (GADPH). The primer sequences used were as follows: Bax forward, 5'-TGCTTCAGGGTTTCATCCAGG-3 and reverse, 5'-TGGCAAAGTAGAAAAGGGCGA-3'; Bcl-2 forward, 5'-CAGCTGCACCTGACGCCCTT-3' and reverse, 5'-GCCTCCGTTATCCTGGATCC-3'; Cyclin D1 forward, 5'-CATCCCAATGTTGTCCG-3' and reverse, 5'-GCAGCC CAATCA GGTCA-3'; CDK4 forward, 5'-CATGTAGACCAG GACCTAAGC-3' and reverse, 5'-AACTGGCGCATCAGA TCCTAG-3', GAPDH, forward 5'-AGAAGGCTGGGGCTC ATTTG-3' and reverse 5'-AGGGGCCATCCACAGTCTTC-3'.

Western blot analysis. Cells, previously treated with CSC $(0,125,250$ or $500 \mu \mathrm{g} / \mathrm{ml})$, were harvested for total protein extraction using RIPA lysis buffer containing phosSTOP
EASYpack and a protease inhibitor cocktail (Roche Diagnostics $\mathrm{GmbH}$, Mannheim, Germany) for $15 \mathrm{~min}$ at $4^{\circ} \mathrm{C}$. Lysates were centrifuged for $15 \mathrm{~min}$ at $12,000 \mathrm{x} \mathrm{g}$ at $4^{\circ} \mathrm{C}$ and supernatants were collected for further analysis. Protein concentrations were measured using a BCA quantification assay (Pierce; Thermo Fisher Scientific, Inc.). Proteins $(50 \mu \mathrm{g})$ were separated using $10 \%$ SDS-PAGE and transferred to PVDF membranes with a $0.45-\mu \mathrm{m}$ pore size (IPVH00010; Millipore, Billerica, MA, USA). Following blocking with $5 \%$ non-fat milk powder at room temperature for $2 \mathrm{~h}$ with the $5 \%$ non-fat milk powder dissolved using TBS with Tween-20 (TBST, pH 8.0) containing $0.1 \%$ Tween. The membranes were incubated with Akt, p-Akt, PI3K, Bcl-2, Bax, Cyclin D1, CDK4 and $\beta$-actin (all 1:1,000) primary antibodies in immunoblot buffer (TBS containing $0.05 \%$ Tween-20 and 5\% non-fat dry milk) overnight at $4^{\circ} \mathrm{C}$. The following day, membranes were washed three times with Tris-buffered saline with Tween-20 (TBST), and then were incubated with HRP-conjugated Goat anti-rabbit IgG secondary antibodies $(1: 5,000)$ for $1 \mathrm{~h}$ at room temperature. Following washes, Clarity Western enhanced chemiluminescence substrate (Bio-Rad Laboratories, Inc., Hercules, CA, US) was used to visualize protein expression using ChemiDoc XRS+ Imaging System (Bio-Rad Laboratories, Inc.). Respective band intensities were quantified using Image Lab software 4.0 (Bio-Rad Laboratories, Inc.). $\beta$-actin was used as the internal control.

Statistical analysis. Data are expressed as the mean \pm standard deviation. One-way analysis of variance was used to compare different experimental groups. Fisher's least significant difference (for equal variances) or Dunnett's correction (for unequal variances) were used as post-hoc tests. Experiments were conducted in triplicate, with the representative results presented. $\mathrm{P}<0.05$ was considered to indicate a statistically significant difference.

\section{Results}

CSC inhibits the viability of SGC-7901 cells. Human SGC-7901 gastric cancer cells were treated with CSC $(0,125,250$ or $500 \mu \mathrm{g} / \mathrm{ml}$ ) for 24,48 and $72 \mathrm{~h}$, and cell viability was measured using an MTT assay. CSC treatment inhibited the viability of SGC-7901 cells in a dose-dependent and time-dependent manner (Fig. 1A). To further confirm the aforementioned results, the morphology of SGC-7901 cells following CSC treatment was examined. Untreated SGC-7901 cells appeared as densely packed, disorganized multilayers. In contrast, cells which were treated with CSC for $24 \mathrm{~h}$ appeared predominantly round and shrunken, with visible cell detachment (Fig. 1B). The results from the present study demonstrated that CSC markedly inhibited the viability of SGC-7901 cells.

CSC inhibits colony formation of SGC-7901 cells. To investigate the colony formation of SGC-7901 cells following CSC treatment at various concentrations, colonies were counted manually after 1 week of culture. Increased concentrations of CSC resulted in a significant decrease in colony size and colony numbers of SGC-7901 cells (Fig. 2 and B). The results from the present study indicated that CSC treatment significantly inhibited the colony formation ability of SGC-7901 cells. 

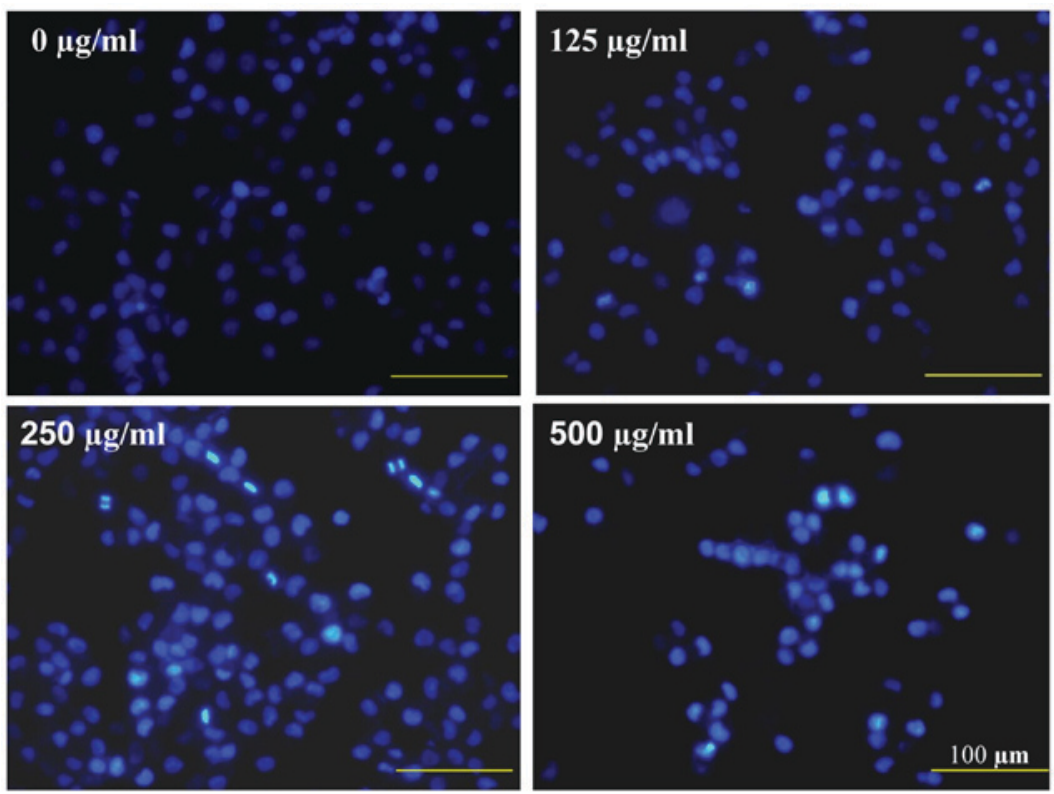

Figure 3. Effects of CSC on the apoptosis of SGC-7901 cells determined by DAPI staining. Cells were treated with the indicated concentrations $(0,125$, $250,500 \mu \mathrm{g} / \mathrm{ml}$ ) of CSC for $24 \mathrm{~h}$. DAPI stained images were recorded using a phase-contrast fluorescence microscope. The images were captured at a magnification, x400. CSC, chloroform extract of Serratulae chinensis S. Moore.
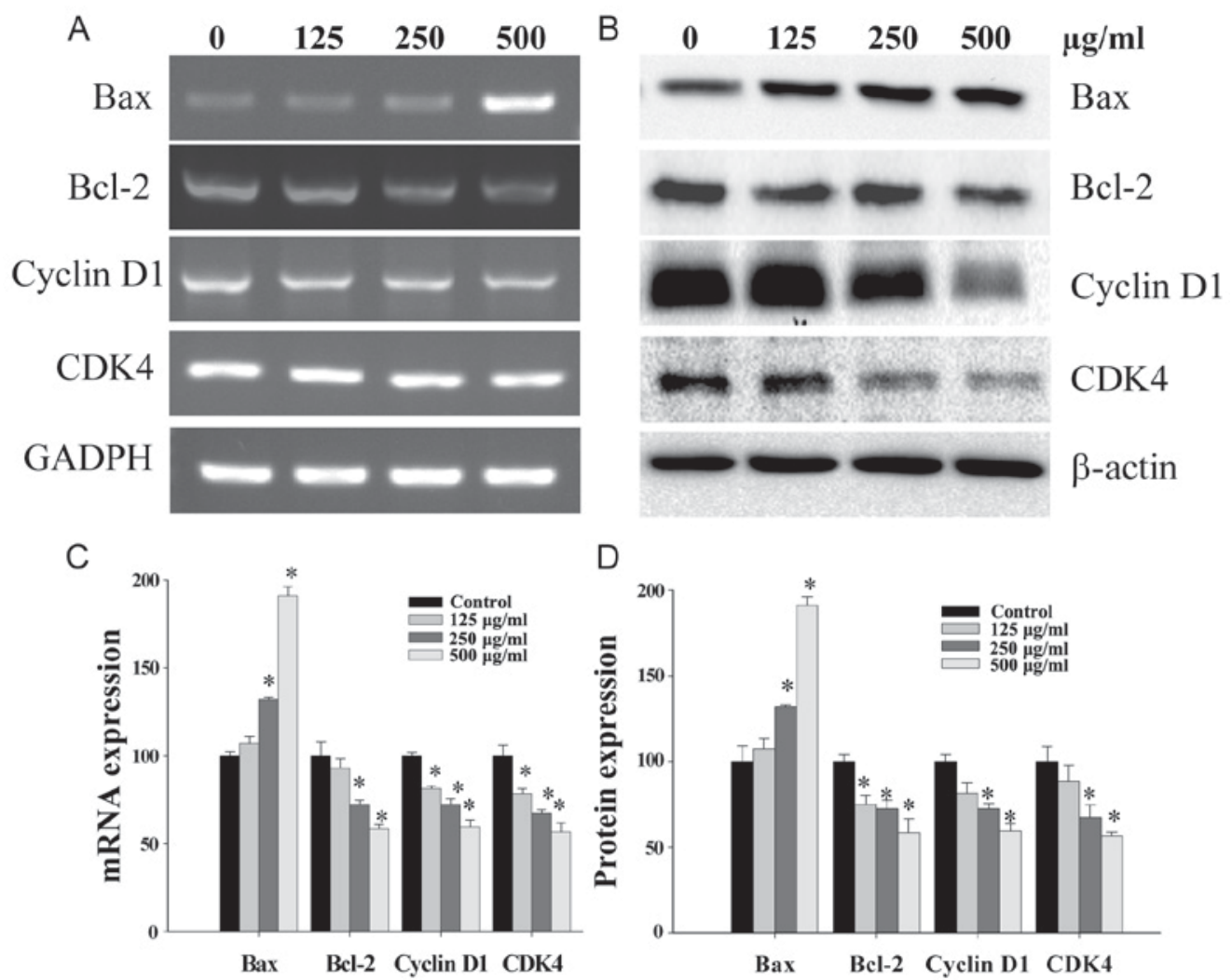

Figure 4. Effects of CSC on the expression of Bcl-2, Bax, Cyclin D1 and CDK4 in SGC-7901 cells. Cells were treated with the indicated concentrations of CSC for $24 \mathrm{~h}$. The mRNA and protein expression of Bcl-2, Bax, Cyclin D1 and CDK4 were evaluated by (A) RT-PCR and (B) Western blot analysis, (C) Analysis of gene expression normalized to GAPDH and (D) respective densitometric analysis of western blots. Data were normalized to the mean mRNA or protein expression of untreated cells $(100 \%)$. "P<0.01 vs. control. CSC, chloroform extract of Serratulae chinensis S. Moore; Bcl-2, B-cell lymphoma-2; Bax, Bcl-2-associated $\mathrm{X}$ protein; CDK4, cyclin-dependent kinase-4; RT-PCR, reverse transcription-polymerase chain reaction; GAPDH, glyceraldehyde 3-phosphate dehydrogenase.

CSC induces apoptosis in SGC-7901 cells. To observe the pro-apoptotic effects of CSC, nuclear morphological changes in SGC-7901 cells was investigated using the DNA-binding dye DAPI. CSC-treated cells demonstrated typical apoptotic morphological features including condensed chromatin and fragmented nuclear morphology, whereas untreated cells 


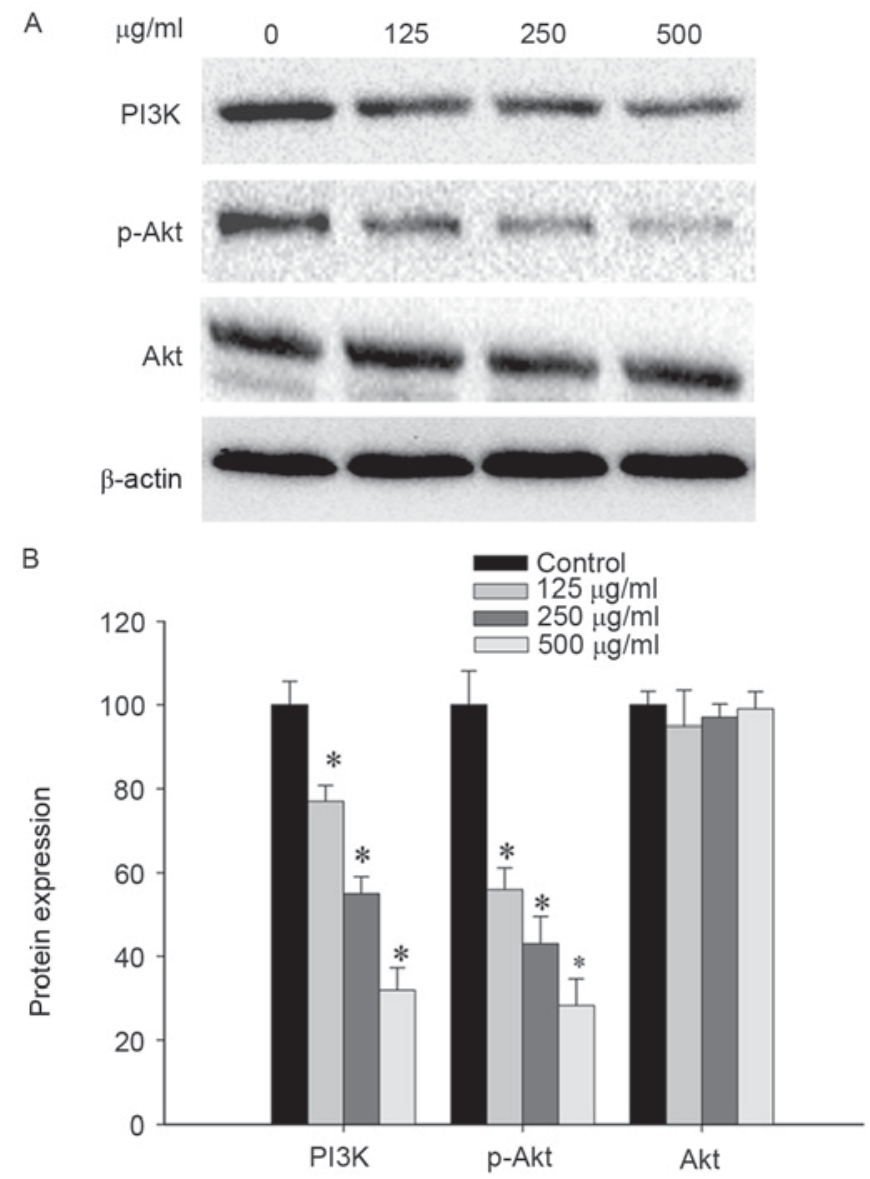

Figure 5. Effects of CSC on p-Akt, Akt and PI3K protein expression in SGC-7901 cells. Cells were treated with the indicated concentrations of CSC for $30 \mathrm{~min}$. (A) Protein expression levels of p-Akt, Akt and PI3K were determined by western blotting. (B) Respective densitometric analysis. Data were normalized to the mean protein expression of untreated cells $(100 \%)$. ${ }^{*} \mathrm{P}<0.01$ vs. control. CSC, chloroform extract of Serratulae chinensis S. Moore; p-phosphorylated; Akt, protein kinase B; PI3K, phosphatidylinositide 3-kinase.

exhibited a homogeneously stained nucleus, yet at a lower intensity (Fig. 3).

Effects of CSC on cell cycle and apoptosis-related proteins. To further investigate the mechanisms underlying the pro-apoptotic and anti-proliferative effects of CSC, RT-PCR and western blot analysis were performed to examine the respective mRNA and protein expression levels of pro-proliferative Cyclin D1 and CDK4, pro-apoptotic Bax and anti-apoptotic Bcl-2. CSC treatment significantly reduced $B c l-2$, Cyclin D1 and CDK4 mRNA expression, but increased Bax expression in SGC-7901 cells (Fig. 4A). In addition, western blot analysis demonstrated that the pattern of protein expression was similar to the respective mRNA expression levels (Fig. 4B).

CSC modulated the PI3K/Akt pathway in SGC-7901 cells. Considering the potential involvement of CSC in the regulation of the PI3K/Akt pathway, the levels of p-Akt, Akt and PI3K protein in SGC-7901 cells following CSC treatment were examined. SGC-7901 cells, treated with CSC at different concentrations $(0,125,250,500 \mu \mathrm{g} / \mathrm{ml})$ for $30 \mathrm{~min}$, demonstrated a significant dose-dependent-reduction in expression levels of PI3K and p-Akt. However, total Akt levels remained unchanged in response to increasing concentrations of CSC (Fig. 5). Taken together, the results from the present study indicated that CSC acts by suppressing the proliferation and promoting the apoptosis of gastric cancer cells, which is mediated by the suppression of the PI3K/Akt pathway.

\section{Discussion}

The underlying molecular mechanisms that accelerate cancer development are complex and involve a multitude of cell signaling transduction pathways. Therefore, a switch from the use of single-drug to multiple-drug chemotherapy for the management and treatment of various types of cancer has occurred (24). Multi-drug treatments aim to regulate the complicated signaling processes responsible for the survival of tumors via the activation or suppression of multiple targets simultaneously (25). TCM has been used extensively in China as a complementary or alternative medicine for multiple diseases. TCM has received renewed interest due to the discovery of its therapeutic anticancer effects, with the advantage of reduced side effects compared with modern chemotherapeutics (26-27). SC is a traditional Chinese herb with multiple reported pharmacological applications (19-21). However, the anticancer benefits of CSC and the mechanisms involved are still largely unknown. Therefore, in order for CSC to be further developed as an anticancer agent, there is an urgent requirement to elucidate the underlying molecular mechanisms involved.

A common feature of cancer cells is a reduction in cell apoptosis and an uncontrolled increase in cell proliferation (28). The Bcl-2 family of proteins are key regulators of apoptosis, which either suppress apoptosis, (for example, Bcl-2), or promote apoptosis (for example, Bax). The ratio of Bax to Bcl-2 determines the fate of cells, and alterations in the ratio caused by aberrant expression of these proteins damages the normal apoptotic routine, thereby contributing to various apoptosis-associated diseases including cancer. An increased $\mathrm{Bcl}-2$ to Bax ratio is associated with poor prognosis in cancers $(28,29)$. Cyclins and CDKs are two important classes of cell cycle regulatory proteins that aid in determining cellular fate during the cell cycle (26). Cyclin D binds to existing CDK4 to form the active Cyclin D/CDK4 complex. Uncontrolled cell division and malignancy are caused by hyperactivated or unchecked Cyclin D1/CDK4 complex $(30,31)$. In the present study, in vitro experiments using gastric cancer SGC-7901 cells revealed the marked anti-proliferative activity of CSC treatment. In addition, CSC treatment markedly increased the pro-apoptotic $\mathrm{Bax} / \mathrm{Bcl}-2$ ratio, whilst downregulating pro-proliferative Cyclin D1 and CDK4 expression. Elucidation of the way CSC induces cell apoptosis and inhibits cell cycle progression may provide a mechanistic basis for an improved understanding of the anticancer effects of such herbal medicines.

The PI3K/Akt signaling pathway is essential for the regulation of cell proliferation and apoptosis. It was previously reported that the activation of $\mathrm{p}$-Akt signaling is increased in gastric cancer tumor samples (32). Following activation by extracellular stimuli, a shift of 
phosphatidylinositol 4,5-bisphosphate to phosphatidylinositol 3,4,5 trisphosphate (PIP3) is induced in the presence of PI3K. The binding of Akt with PIP3 in the pleckstrin homology domain of Akt causes phosphorylation at Thr308 on its activation loop by plasma membrane localized 3-phosphoinositide-dependent protein kinase 1 (PDK1) (33). PDK-1 over-activation leads to increased p-Akt, which in turn regulates the expression of various key genes involved in cell proliferation and apoptosis, including Bcl-2, Bax, Cyclin D1 and $C D K 4(34,35)$. Multiple PI3K or Akt inhibitors are currently in use in clinical or preclinical studies (36). LY294002, the first developed PI3K inhibitor, was demonstrated to inhibit cell proliferation in several cancer cell lines and was able to to potentiate the effects of chemotherapy (37-40). Therefore, a re-balance in cell proliferation and apoptosis via regulation of the PI3K/Akt pathway and its downstream target gene expression is a promising route for the development of anticancer therapies. In the present study, it was observed that CSC inhibited cell viability and induced apoptosis in gastric cancer cells. Furthermore, CSC significantly inhibited the expression of PI3K and p-Akt in a dose-dependent manner, via upregulating Bax expression and downregulating Cyclin D1, CDK4 and Bcl-2 expression, which are major gene targets of the PI3K/Akt pathway.

In conclusion, the present study demonstrated for the first time that CSC was able to inhibit the PI3K/Akt signaling pathway, leading to the inhibition of cell viability, whilst inducing apoptosis in gastric cancer cells. Thus, CSC may be a potential novel therapeutic agent for the treatment of gastric cancer.

\section{Acknowledgements}

Not applicable.

\section{Funding}

The present study was funded by the National Natural Science Foundation of China (grant no. 81403390) and the University of Distinguished Young Research Talent Training Program of Fujian.

\section{Availability of data and materials}

All data generated or analyzed during this study are included in this published article.

\section{Author's contributions}

QC and JP conceived and designed the study. QC, JL, LZ and SL performed the experiments. QC wrote the paper, and JP reviewed and edited the manuscript. All authors read and approved the final manuscript.

\section{Ethics approval and consent to participate}

Not applicable.

\section{Consent for publication}

Not applicable.

\section{Competing interests}

The authors declare that they have no competing interests.

\section{References}

1. Zhu S, Soutto M, Chen Z, Peng D, Romero-Gallo J, Krishna US, Belkhiri A, Washington MK, Peek $\mathrm{R}$ and El-Rifai W: Helicobacter pylori-induced cell death is counteracted by NF- $\kappa \mathrm{B}-$-mediated transcription of DARPP-32. Gut 66: 761-762, 2017.

2. Torre LA, Bray F, Siegel RL, Ferlay J, Lortet-Tieulent J and Jemal A: Global cancer statistics, 2012. CA Cancer J Clin 65: 87-108, 2015.

3. Power DG, Kelsen DP and Shah MA: Advanced gastric cancer-slow but steady progress. Cancer Treat Rev 36: 384-392, 2010.

4. Park HR, Tomida A, Sato S, Tsukumo Y, Yun J, Yamori T, Hayakawa Y, Tsuruo T and Shin-ya K: Effect on tumor cells of blocking survival response to glucose deprivation. J Natl Cancer Inst 96: 1300-1310, 2004.

5. Li XJ and Zhang HY: Western healers in traditional Chinese medicine. EMBO Rep 9: 112-113, 2008.

6. Schmidt BM, Ribnicky DM, Lipsky PE and Raskin I: Revisiting the ancient concept of botanical therapeutics. Nat Chem Biol 3: 360-366, 2007.

7. Zhao J, Jiang P and Zhang W: Molecular networks for the study of TCM pharmacology. Brief Bioinform 11: 417-430, 2010.

8. Meng Z, Garrett CR, Shen Y, Liu L, Yang P, Huo Y, Zhao Q, Spelman AR, Ng CS, Chang DZ and Cohen L: Prospective randomised evaluation of traditional Chinese medicine combined with chemotherapy: A randomised phase II study of wild toad extract plus gemcitabine in patients with advanced pancreatic adenocarcinomas. Br J Cancer 107: 411-416, 2012.

9. Wang Y, Jin F, Higgins R and Mcknight K: The current view for the silencing of the spindle assembly checkpoint. Cell Cycle 13: 1694-1701, 2014.

10. Chang F, Lee JT, Navolanic PM, Steelman LS, Shelton JG, Blalock WL, Franklin RA and McCubrey JA: Involvement of PI3K/Akt pathway in cell cycle progression, apoptosis, and neoplastic transformation: A target for cancer chemotherapy. Leukemia 17: 590-603, 2003.

11. Zhang XB, Song L, Wen HJ, Bai XX, Li ZJ and Ma LJ: Upregulation of microRNA-31 targeting integrin $\alpha 5$ suppresses tumor cell invasion and metastasis by indirectly regulating PI3K/AKT pathway in human gastric cancer SGC7901 cells. Tumour Biol 37: 8317-8325, 2016.

12. Franke TF, Kaplan DR and Cantley LC: PI3K: Downstream AKTion blocks apoptosis. Cell 88: 435-437, 1997.

13. Franke TF, Yang SI, Chan TO, Datta K, Kazlauskas A, Morrison DK, Kaplan DR and Tsichlis PN: The protein kinase encoded by the Akt proto-oncogene is a target of the PDGF-activated phosphatidylinositol 3-kinase. Cell 81: 727-736, 1995.

14. Okuzumi T, Fiedler D, Zhang C, Gray DC, Aizenstein B, Hoffman R and Shokat KM: Inhibitor hijacking of Akt activation. Nat Chem Biol 5: 484-493, 2009

15. Pugazhenthi S, Nesterova A, Sable C, Heidenreich KA, Boxer LM, Heasley LE and Reusch JE: Akt/protein kinase B up-regulates Bcl-2 expression through cAMP-response element-binding protein. J Biol Chem 275: 10761-10766, 2000.

16. Qian J, Zou Y, Rahman JS, Lu B and Massion PP: Synergy between phosphatidylinositol 3-kinase/Akt pathway and Bcl-xL in the control of apoptosis in adenocarcinoma cells of the lung. Mol Cancer Ther 8: 101-109, 2009.

17. Liu CY, Shiau CW, Kuo HY, Huang HP, Chen MH, Tzeng CH and Chen KF: Cancerous inhibitor of protein phosphatase $2 \mathrm{~A}$ determines bortezomib-induced apoptosis in leukemia cells. Haematologica 98: 729-738, 2013.

18. Chen KF, Yeh PY, Yeh KH, Lu YS, Huang SY and Cheng AL: Down-regulation of phospho-Akt is a major molecular determinant of bortezomib-induced apoptosis in hepatocellular carcinoma cells. Cancer Res 68: 6698-6707, 2008.

19. Ling TJ, Xia T, Wan XC, Li DX and Wei XY: Cerebrosides from the roots of Serratula chinensis. Molecules 11: 677-683, 2006.

20. Ling TJ, Ping WU, Liu MF and Wei XY: Ceramides from the roots of Serratula chinensis. J Trop Subtrop Botany 13: 403-407, 2005 . 
21. Abdel Hadi L, Di Vito C, Marfia G, Ferraretto A, Tringali C, Viani $\mathrm{P}$ and Riboni L: Sphingosine kinase 2 and ceramide transport as key targets of the natural flavonoid luteolin to induce apoptosis in colon cancer cells. PloS One 10: e0143384, 2015.

22. Liu Y, Zhu Z, Fei SJ, Liu L and Sun M and Zhang Q: Ceramide promoting apoptosis of SGC7901 cell. Cancer Res Prev Treat: 991-994, 2011.

23. Zhang L, Cai Q, Lin J, Fang Y, Zhan Y, Shen A, Wei L, Wang L and Peng J: Chloroform fraction of Scutellaria barbata D. Don promotes apoptosis and suppresses proliferation in human colon cancer cells. Mol Med Rep 9: 701-706, 2014.

24. Petrelli A and Giordano S: From single- to multi-target drugs in cancer therapy: When aspecificity becomes an advantage. Curr Med Chem 15: 422-432, 2008.

25. Gagliostro V, Casas J, Caretti A, Abad JL, Tagliavacca L, Ghidoni R, Fabrias G and Signorelli P: Dihydroceramide delays cell cycle G1/S transition via activation of ER stress and induction of autophagy. Int J Biochem Cell Biol 44: 2135-2143, 2012.

26. Wang X, Feng Y, Wang N, Cheung F, Tan HY, Zhong S, Li C and Kobayashi S: Chinese medicines induce cell death: The molecular and cellular mechanisms for cancer therapy. Biomed Res Int 2014: 530342, 2014.

27. Li-Weber M: Targeting apoptosis pathways in cancer by Chinese medicine. Cancer Lett 332: 304-312, 2013.

28. Adams JM and Cory S: The Bcl-2 apoptotic switch in cancer development and therapy. Oncogene 26: 1324-1337, 2007.

29. Youle RJ and Strasser A: The BCL-2 protein family: Opposing activities that mediate cell death. Nat Rev Mol Cell Biol 9: 47-59, 2008.

30. Muntean AG, Pang L, Poncz M, Dowdy SF, Blobel GA and Crispino JD: Cyclin D-Cdk4 is regulated by GATA-1 and required for megakaryocyte growth and polyploidization. Blood 109: 5199-5207, 2007.

31. Nigg EA: Cyclin-dependent protein kinases: Key regulators of the eukaryotic cell cycle. Bioessays 17: 471-480, 1995.
32. Orlando DA, Lin CY, Bernard A, Wang JY, Socolar JE, Iversen ES, Hartemink AJ and Haase SB: Global control of cell-cycle transcription by coupled CDK and network oscillators. Nature 453: 944-947, 2008

33. Johnson SM, Gulhati P, Rampy BA, Han Y, Rychahou PG, Doan HQ, Weiss HL and Evers BM: Novel expression patterns of $\mathrm{PI} 3 \mathrm{~K} / \mathrm{AKT} / \mathrm{mTOR}$ signaling pathway components in colorectal cancer. J Am Coll Surg 210: 767-778, 2010.

34. Umemura S, Yoshida S, Ohta Y, Naito K, Osamura RY and Tokuda Y: Increased phosphorylation of Akt in triple-negative breast cancers. Cancer Sci 98: 1889-1892, 2007.

35. Datta SR, Brunet A and Greenberg ME: Cellular survival: A play in three Akts. Genes Dev 13: 2905-2927, 1999.

36. Liu G, Song Y, Cui L, Wen Z and Lu X: Inositol hexaphosphate suppresses growth and induces apoptosis in HT-29 colorectal cancer cells in culture: PI3K/Akt pathway as a potential target. Int J Clin Exp Pathol 8: 1402-1410, 2015.

37. Badinloo M and Esmaeili-Mahani S: Phosphatidylinositol 3-kinases inhibitor LY294002 potentiates the cytotoxic effects of doxorubicin, vincristine, and etoposide in a panel of cancer cell lines. Fundam Clin Pharmacol 28: 414-422, 2014.

38. Yang ZP, Zhao Y, Huang F, Chen J, Yao YH, Li J and Wu XN Equol inhibits proliferation of human gastric carcinoma cells via modulating Akt pathway. World J Gastroenterol 21: 10385-10399, 2015.

39. Wu D, Tao J, Xu B, Qing W, Li P, Lu Q and Zhang W: Phosphatidylinositol 3-kinase inhibitor LY294002 suppresses proliferation and sensitizes doxorubicin chemotherapy in bladder cancer cells. Urol Int 86: 346-354, 2011.

40. Xia LJ, Wu YL and Zhang FC: Combination of cecropinXJ and LY294002 induces synergistic cytotoxicity, and apoptosis in human gastric cancer cells via inhibition of the PI3K/Akt signaling pathway. Oncol Lett 14: 7522-7528, 2017. 